\title{
Taking Stock Of Health: An Examination Of Health Insurance Expenditures By Employer Categories
}

Swarn Chatterjee, University of Georgia, USA

John Gilliam, Texas Tech University, USA

\begin{abstract}
This research uses the Consumer Expenditure Survey (CEX) data to examine the cost of health insurance coverage for government as well as private sector employees and for the self-employed. The findings show that, when compared with private-sector employees, the self-employed spend more and government employees spend less on health insurance premium payments. Factors such as education, marital status, region of residence, age, family size and educational attainment are significant determinants of the amount spent on health insurance. In addition, the likelihood of participation in Preferred Provider Option (PPO) health plans is lower for government employees and for self-employed individuals than for private sector employees.
\end{abstract}

Keywords: Health insurance, employee participation, insurance premiums, PPO

\section{INTRODUCTION}

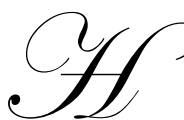

ealth insurance provides important protection against rising healthcare costs and increases individuals' access to quality healthcare. Employers view health insurance as an important form of employee benefit that helps to retain and recruit new employees. A 2003 study of the healthcare industry indicated that the per capita healthcare cost in the United States will continue to increase over the next several years (Porter, 2003). As a result of rising healthcare costs, health insurance premiums have also increased, and private employers are trying to cope with escalating costs of premiums by passing them on to their employees. In fact, a 2002 study showed that approximately 22\% of the costs of insurance premiums were paid by the employees (Strunk, Ginsburg \& Gabel, 2002). According to another report, governmental agencies contributed a greater percentage of the cost of healthcare insurance for their employees than the private sector (Zawacki \& Taylor, 2005).

The purpose of this research is to determine, after controlling for other socioeconomic and demographic factors, which group spends more on healthcare insurance premiums: those employed in the private and public sectors or those who are self-employed. This study also determines whether payment of health insurance premiums constitutes a greater percentage of annual household consumption for government employees, private employees or the self-employed. Finally, the study addresses whether the likelihood of participation in the PPO health plans varies with the type of employment. We use the 2003 Consumer Expenditure Survey, a large nationally representative database maintained by the Bureau of Labor Statistics, to estimate the determinants of health insurance premium spending and PPO participation among privately employed, government employed and self-employed individuals.

\section{LITERATURE REVIEW}

Health insurance coverage provides access to healthcare for individuals. Past research provides ample evidence that access to healthcare is a predictor of physical well being among the insured (Bindman, Grumbach \& Osmond., 1996; Starfield, 1995) and that the uninsured were less likely to receive adequate care for their chronic health conditions (Lurie, Ward, Shapiro \& Brook, 1984).The existing health insurance system is either voluntary or 
employment-based. Healthcare costs have risen rapidly over the past several years (Strunk et al., 2002). In order to reduce their costs, employers are increasing deductibles and co-payments and reducing contributions for dependent coverage, thereby shifting more of the costs to employees (Ginsburg, 2004). Fronstin (2004) found that the selfemployed (49.6\%) were less likely to have employment-based health insurance coverage than public sector (87.4\%) or private sector employees (70.2\%). Lucas (2008) discussed various strategies that can help to reduce employer costs and distribute the costs and responsibilities of insurance coverage between employers and employees.

As for other demographic findings related to health insurance and healthcare, Zawacki and Taylor (2005) found that employees in the South were more likely to pay a larger portion of their health insurance premiums, while employees in the West had to pay a lower percentage of their premiums. The likelihood of a person's being insured in the South was lower than in the West, Midwest and Northeast (Paulin \& Duly, 2002).Adler and Newman (2002) concluded in their study that socioeconomic factors such as income, educational attainment and employment status accounted for most of the differences in insurance participation among individuals, while Starr-McCluer (1996) found that insured households saved more than households without coverage. . Paulin and Duly (2002) found that healthcare expenses for the elderly were more than those of the non-elderly. Sharpe and Hong (2002) also found that age was a significant factor in rising household healthcare costs and that healthcare consumption increased with educational attainment. Paulin and Duly (2002) also found that married households spent more on healthcare per person than did single and non-married households.

To summarize the findings of past studies, most employers subsidize or defray part of the premium costs of health insurance for the private and government employees, but the self-employed have to bear the entire cost of their insurance premium payments and, therefore, are likely to spend more on their health insurance premiums than others. In addition, while health insurance premiums are likely to form a major portion of expenses for the selfemployed, the private and government employees for whom the employer pays a portion of their insurance premiums are more likely to participate in the PPO plans. Hence, based on existing literature and past studies, the following hypotheses have been developed.

Hypothesis 1: The self-employed have higher healthcare insurance premium costs than other groups.

Hypothesis 2: The self-employed spend a larger proportion of their annual expenses in health insurance premiums than other groups.

Hypothesis 3: $\quad$ Private and government employees are more likely than the self-employed to participate in PPOtype health plans.

\section{METHODOLOGY}

\section{Data}

The data was obtained from the 2003 Consumer Expenditure survey (CEX), which is an ongoing survey that provides a regular flow of information on the buying habits of American consumers and furnishes data to support periodic revisions of the Consumer Price Index. The Consumer Unit Characteristics and Income (FMLY) files contain consumer unit characteristics, income, and earnings of household members. The Member Characteristics and Income (MEMB) files contain selected characteristics for each consumer unit member, including the respondent and spouse. Each record in the FMLY and MEMB files consists of three months of data (Nelson, 1994).

\section{Variables}

The research included 14,925 consumer units (CUs), which were separated into three groups. The largest group was comprised of the private sector employees, followed by those employed by various government and government agencies and, finally, those who were self-employed. Each group was examined to determine the amount of premiums spent on various types of healthcare insurance. The insurance premiums represent the premiums paid for healthcare, dental, vision, prescription drug, mental health, dread disease, and other types of special purpose health insurance. 
Among the variables chosen for this research, marital status, region, housing type (tenure), family size, income, annual expense, age, race, gender, and educational attainment were selected from the FMLY file of the CEX. The variables for the amount of health insurance premium paid and type of insurance plan were obtained from the IHB file of the CEX. For the purposes of this study, only primary-income earners between 18 and 65 years of age were considered, and the study excluded respondents who received Medicaid or other forms of welfare assistance.

\section{Analysis}

A multivariate regression analysis was first performed to test whether the self-employed spent more on health insurance premiums than other groups, after controlling for various socio-economic and demographic factors. Three separate regression analyses were then performed to estimate the determinants of amounts spent on health insurance premiums by the privately employed, government employed and self-employed respondents. The dependent variable used for this study was the amount of annual health insurance cost. Log form of the dependent variable was used to suppress outlier effects.

The above analyses were then followed by another OLS regression to estimate whether health insurance accounted for a larger proportion of annual consumption expenses for the self-employed than for other groups. The dependent variable was constructed by calculating the ratio of insurance premium payment to annual expenses, and the $\log$ form of the dependent variable was used in this model. Finally, a probit analysis was performed to estimate the likelihood of participation in Preferred Provider Option (PPO) health plans for each of the three employment groups; the dependent variable was coded as ' 1 ' for participation in a PPO plan and as ' 0 ' if otherwise.

\section{RESULTS}

\section{Descriptive Statistics}

The descriptive statistics in Table 1 show that a majority of the respondents in this study were privately employed individuals (74.4\%). Among the respondents, a higher percentage of the privately employed (56\%) and self-employed (69\%) were men, although the proportion of men $(49 \%)$ and women $(51 \%)$ working for the government were almost equal. The government employees had the highest percentage of respondents with attainment of a college degree or higher. The privately employed and the self-employed had a higher annual income than the government employees. The self-employed had the highest annual expense and the highest rate of homeownership among the three groups.

\section{Determinants of the Cost of Health Insurance Premium Payments}

Table 2 shows the OLS regression estimates of the determinants of annual health insurance premiums paid for the overall sample, as well as separately for the three employment-type groups. The results show that, consistent with past studies (Fronstin, 2004; Zawacki \& Taylor, 2005), those who worked for the government had lower insurance premium costs (Beta=-.147, $\mathrm{p}<.001)$ and those who were self-employed (Beta=.634, $\mathrm{p}<.001)$ paid more on their health insurance premiums than did the reference group of privately employed individuals.

Among other control variables, as found in earlier studies (Fronstin, 2004; Fan et al., 2000), when compared with the reference age group of those over age 51, the younger age groups had lower insurance premium payments in the overall sample as well as for the privately employed and government employed groups. Among the self-employed, those under age 33 and between age 42 and age 51 had significantly lower insurance premium costs than did the reference age group. When compared with those who were single, the married, divorced or separated and widowed respondents had higher health insurance premium costs in the overall sample, as well as in the privately employed group. Consistent with past findings (Paulin \& Duly, 2002), the married respondents also paid significantly higher insurance premiums in the government employed and self-employed groups. The divorced or separated individuals who were self-employed also had higher health insurance premium costs than the reference group. As found in earlier studies (Hanson, 2001), family size was a positive predictor of the cost of health insurance premium payments for the overall group as well as for the privately employed and government employed 
groups. Compared to those who lived in the Western United States, individuals who lived in the Northeast, South and Midwest had higher insurance premium costs in the overall sample, findings that agree with those of past research (Gabel, 1999). In addition, the relationship between region and cost of premiums was also significant among the privately employed and the self-employed groups. Among those who worked for the government, the employees who lived in the North and South had higher insurance premium costs than those who lived in the West.

There was also a significant relationship between educational attainment and cost of health insurance premium; the results show that, when compared with the reference group of individuals with educational attainment of less than high school, those who had higher educational attainment paid more on their health insurance in the overall sample as well as in the privately employed group. Health insurance premium costs were significantly higher for those who had educational attainment of a college degree or higher among the self-employed. These results confirm the findings of past studies (Paulin \& Duly, 2002; Adler \& Newman, 2002). The relationship between educational attainment and cost of premiums was not significant among government employees.

Income was a significant predictor of the cost of health insurance premium in the overall sample and among the privately employed and self-employed groups. The insurance costs however, did not vary significantly by income among the government-employed individuals. Home ownership was a significant predictor of the cost of health insurance premium in the overall sample and among privately employed individuals, but the relationship between premium cost and home ownership was not significant for other groups.

\section{Cost of Health Insurance Premium as a proportion of annual expenses}

The results from Table 3 show, as did the Hong and Marquis (1999) study, that the cost of health insurance premiums as a proportion of annual expenses, was likely to be lower for government employees and higher for the self-employed than for those who were privately employed. Also, among those age 51 and younger, health insurance premiums constituted a lower proportion of annual expenses than they did for the individuals aged 52 or older. Being married and larger family size were positively associated with having higher costs of health insurance as a percentage of annual expenses. In addition, those who lived in the northeastern, southern and midwestern United States spent more on health insurance premiums as a proportion of their annual expenses than did those who lived in the west. Income and educational attainment of college or higher were positively associated with higher cost of insurance as a percentage of annual expenses.

\section{Likelihood of Participation in PPO Plans}

The probit estimation of likelihood of participation in PPO plans (Table 4) shows that the self-employed and government employed individuals were less likely to participate in PPO types of plans than were the privately employed. These findings are in opposition to those of Long and Marquis (1999), who found a 38\% PPO participation among government employees and a 36\% PPO participation rate for private employees. In our study, among other variables, those who were between 33 and 51 years of age were more likely to participate in PPO plans than those who were 52 and older. Also, compared to those who lived in the west, individuals living in the northeast were less likely and those living in the south more likely to participate in PPO plans. In addition, educational attainment of high school or higher was positively associated with participation in PPO plans, and, possibly by association with educational attainment, income was a positive predictor of participation in PPO plans.

\section{DISCUSSION}

The purpose of this research was to find some of the determinants that may affect health insurance consumption. Most of the individuals working in corporate America, as well those working for the various local, state and federal governments, have healthcare insurance coverage available to them —or at least subsidized — as a form of employee benefit. This research addresses whether there is a significant difference in the healthcare insurance consumption between government, private and self employed individuals.

The findings from this research (Table 2) confirm the first hypothesis that the self-employed spend more and that government employees spend less on healthcare insurance than do those working in the private sector. This 
finding may result from government employees' receiving greater assistance on the defrayal of their health insurance premium costs from their employment than other groups. The self-employed, on the other hand, receive the least amount of assistance in this regard and, as a result, have a much higher cost of health insurance participation.

Older individuals, who face the prospect of deteriorating health, may see higher premium costs because they participate in plans with lower deductibles or participate in other forms of supplementary coverage that drive up the cost of their health insurance coverage. As a result, younger individuals have a lower cost of health insurance than do those who are 51 or older. When compared with those that are single, the married, widowed or divorced probably have more dependents and, therefore, pay a higher amount of health insurance premiums than those who are single. Income and educational attainment are determinants of the cost of health insurance participation across all groups except the government employees perhaps because the quality of health insurance offered to the employees in the private sector is contingent upon their educational qualifications, position and income; as a result, better qualified, higher-income employees in the private sector have access to insurance plans with better coverage and lower deductibles, which also require payment of a higher premium. Among the self-employed, those who are highly qualified or are in higher income brackets are likely to participate in insurance plans with lower deductibles and better coverage, while those who have lower income may choose to participate in higher-deductible plans, essentially "self-insuring" for their more minor medical needs. The government employees are an exception in this regard, because government employment offers the same suite of plans to all employees.

The results shown in Table 3 confirm the hypothesis that health insurance premium payments constitute a higher percentage of annual consumption expenses for the self-employed than for the reference group of the privately employed. It is possible that, although the annual health insurance premium payments were lower for government employees (Table 1) than for employees in the private sector, the ratio of their health insurance premium payment as a percentage of annual consumption is higher because of their lower average annual income. However, the results shown in Table 3 indicate that this conjecture is not the case and that government employees spend a lower percentage of their annual consumption expenses on health insurance payments than do those who are employed in the private sector. In addition, the cost of insurance premium payments as a percentage of annual expenses declines with income and educational attainment, probably because higher income and educational attainment enables individuals to afford a larger and more expensive array of goods and services and, as a result of this, the cost of health insurance as a percentage of annual consumption declines with income and educational attainment.

The results shown in Table 4 indicate that, even though the cost of health insurance premiums were lower for government employees, these employees were less likely to participate in the PPO type of plans than were privately employed individuals. One possible explanation is a greater availability of HMO's to government employees than privately and self-employed individuals. This finding may explain why the cost of premium payments were lower for government employees. The self-employed, who have to pay the entire cost of their premium out of pocket, were less likely to participate in the PPO type of plans than were the privately employed individuals.

\section{CONCLUSION}

The results of this study show that healthcare consumption has not been uniform across the country. Differences have been observed in the level of healthcare consumed based on educational and marital status, family size and income levels. Although the empirical analysis shows that the self-employed are likely to spend more and government employees are likely to spend less on their health insurance premiums than the privately employed, since companies and governmental employers make considerable contributions to premiums, the data collected does not show the full cost of all healthcare insurance consumption.

As the nation struggles with rampant increases in healthcare, it is apparent that a more comprehensive solution to the problem of providing adequate healthcare and healthcare insurance coverage must be found to keep the healthcare insurance premiums for employers and individuals within manageable limits. As Lucas (2008) suggested, private employers and businesses should emphasize offering plans that share the costs of the premium 
payments with the employees. Another concern is the cost of accessing healthcare for the self-employed. Some form of incentive - perhaps a tax break or an option to participate in a group coverage type of plan - could provide an impetus for greater participation in health insurance plans and result in defrayal of cost of healthcare for the selfemployed. As costs continue to climb, a debate concerning this enormous issue of healthcare reform will need to be addressed soon in order to help enable business leaders, policymakers and consumers work towards a better solution for healthcare accessibility and health insurance consumption.

\section{AUTHOR INFORMATION}

Swarn Chatterjee is an Assistant Professor in the Department of Housing and Consumer Economics at the University of Georgia. He has a Ph.D. and an MBA from Texas Tech University. His research interests include individual investment behavior, economics of immigration, income uncertainty, and health insurance participation, social security and welfare dynamics.

John Gilliam an assistant professor in the Division of Personal Financial Planning at Texas Tech University. His academic life is strongly influenced by almost 30 years of professional experience as a financial advisor. His research interests include the assessment of financial risk tolerance in couples, the impact of behavioral heuristics and biases in financial planning, Intra-cohort differences among Baby boomers, and health care considerations during retirement. He is a Certified Financial Planner ${ }^{\mathrm{TM}}$, Charter Life Underwriter and Chartered Financial Consultant.

\section{REFERENCES}

1. Adler, N.E. \& Newman, K. (2002). Socioeconomic disparities in health: Pathways and Policies. Health Affairs, 21(2), 60-76

2. Bindman, A. K., Grumbach, K., \& Osmond., D. (1996). Accuracy of preventable hospitalization rates for measuring access to care in rural communities. Journal of General Internal Medicine, 11 (supplement), 64.

3. Fan, J, Sharpe, D \& Hong, G.S (2000). Household Out of Pocket Health Care Expenditure Patterns: A Longitudinal Study of 1980-1995. Consumer Interest Annual, 46

4. Fronstin, P. (2004). Sources of health insurance and characteristics of the uninsured: Analysis of the March 2006 Current Population Survey. Issue Brief No.276. Washington, DC: Employee Benefits Research Institute.

5. Gabel, J. (1999). Job-based health insurance, 1977-1998: the accidental system under scrutiny. Health Affairs, 18, 62-74

6. Ginsburg, P (2004). Controlling Health Care Costs. The New England Journal of Medicine, 351(16), 15911593

7. Gruber, J \& McKnight, R (2003). Why did Employee Health Insurance Contributions Rise. Journal of Health Economics. 22(2003)1085-1104

8. Hanson, K.L. (2001). Patterns of insurance coverage within families with children. Health Affairs, 20(1), 240-246.

9. Long, S.H. \& Marquis, M.S. (1999). Comparing employee health benefits in the private and public sectors, 1997. Health Affairs, 18(6), 183-193

10. Lucas, J. (2008). Health care delivery crisis in corporate America. Journal of Business and Economics Research, 6(3), 41-46

11. Lurie, N., Ward, N.B., Shapiro, M.F. \& Brook, R.H. (1984). Termination from Medi-Cal: does it affect health? New England Journal of Medicine, 310, 480-484

12. Nelson, J. (1994). On testing for full insurance using Consumer Expenditure Survey data. Journal of Political Economy, 102(2), 384

13. Paulin, G \& Duly, A (2002). Planning Ahead: Consumer Expenditure Patterns in Retirement. Monthly Labor Review, 125, 38-58

14. Porter, M. (2003). The economic performance of regions. Regional Studies: The Journal of Regional Studies Association, 37(7), 545-546

15. Starfield B. (1995). Access: perceived or real, and to what? Journal of American Medical Association, 274(4), 346-347 
16. Starr-McCluer, M. (1996). Health insurance and precautionary savings. The American Economics Review, 86(1), 285-295

17. Strunk, B.C., Ginsburg, P.B. , Gabel, J.R.(2002). Tracking Health Care Costs: Growth Accelerates Again in 2001. Health Affairs Web Exclusives: W299.

18. Zawacki, A. \& Taylor, A. (2005). Contributions to Health Insurance Premiums: When Does the Employer Pay 100 Percent? Working Papers 05-27, Center for Economic Studies, U.S. Census Bureau

Table 1. Descriptive Statistics

\begin{tabular}{|c|c|c|c|c|}
\hline & Overall & $\begin{array}{l}\text { Privately } \\
\text { Employed }\end{array}$ & $\begin{array}{l}\text { Government } \\
\text { Employed }\end{array}$ & $\begin{array}{l}\text { Self } \\
\text { Employed }\end{array}$ \\
\hline Overall & $100 \%$ & $74.40 \%$ & $16.28 \%$ & $9.32 \%$ \\
\hline Average Age & 42.3 & 41.2 & 43.3 & 48.6 \\
\hline \multicolumn{5}{|l|}{ Gender } \\
\hline Male & $56 \%$ & $56 \%$ & $49 \%$ & $69 \%$ \\
\hline Female & $44 \%$ & $44 \%$ & $51 \%$ & $31 \%$ \\
\hline Married & $55 \%$ & $54 \%$ & $55 \%$ & $64 \%$ \\
\hline Family size & 2.68 & 2.7 & 2.6 & 2.63 \\
\hline \multicolumn{5}{|l|}{ Race } \\
\hline White & $83 \%$ & $83 \%$ & $80 \%$ & $90 \%$ \\
\hline Black & $12 \%$ & $12 \%$ & $16 \%$ & $6 \%$ \\
\hline Others & $5 \%$ & $5 \%$ & $4 \%$ & $4 \%$ \\
\hline \multicolumn{5}{|l|}{ Region } \\
\hline North Central & $18 \%$ & $19 \%$ & $16 \%$ & $17 \%$ \\
\hline Mid West & $24 \%$ & $24 \%$ & $23 \%$ & $22 \%$ \\
\hline South & $35 \%$ & $35 \%$ & $39 \%$ & $34 \%$ \\
\hline West & $23 \%$ & $22 \%$ & $22 \%$ & $27 \%$ \\
\hline \multicolumn{5}{|l|}{ Educational Attainment } \\
\hline Less than High School & $10 \%$ & $11 \%$ & $4 \%$ & $11 \%$ \\
\hline High School & $28 \%$ & $29 \%$ & $20 \%$ & $25 \%$ \\
\hline Some College & $32 \%$ & $33 \%$ & $31 \%$ & $30 \%$ \\
\hline College & $20 \%$ & $19 \%$ & $24 \%$ & $21 \%$ \\
\hline Grad/Prof Degree & $10 \%$ & $8 \%$ & $21 \%$ & $13 \%$ \\
\hline Income & $\$ 44,079.47$ & $\$ 44,575.34$ & $\$ 42,257.27$ & $\$ 43,304$ \\
\hline Annual Expenses & $\$ 21,376.14$ & $\$ 21,283.63$ & $\$ 20,079.28$ & $\$ 24,379.98$ \\
\hline Homeowner & $64 \%$ & $61 \%$ & $71 \%$ & $80 \%$ \\
\hline
\end{tabular}


Table. 2. Regression analysis: Contribution of health insurance premium

\begin{tabular}{|c|c|c|c|c|c|c|c|c|c|c|c|c|}
\hline \multirow[b]{2}{*}{ Age (ref.: >51) } & \multicolumn{3}{|l|}{ Overall } & \multicolumn{3}{|c|}{ Privately Employed } & \multicolumn{3}{|c|}{ Government Employed } & \multicolumn{3}{|c|}{ Self Employed } \\
\hline & Coef & St.Error & Sig & Coef & St.Error & Sig. & Coef & St.Error & Sig. & Coef & St.Error & Sig. \\
\hline Age $<33$ & -0.300 & 0.047 & $* * *$ & -0.298 & 0.053 & $* * *$ & -0.437 & 0.127 & $* * *$ & -0.327 & 0.198 & $*$ \\
\hline Age 3341 & -0.156 & 0.042 & $* * *$ & -0.114 & 0.048 & $* *$ & -0.502 & 0.109 & $* * *$ & -0.032 & 0.146 & \\
\hline Age 4251 & -0.080 & 0.041 & $* *$ & -0.096 & 0.048 & $* *$ & -0.196 & 0.100 & $* *$ & -0.259 & 0.125 & $* *$ \\
\hline Male (ref.: female) & 0.008 & 0.031 & & -0.036 & 0.035 & & 0.183 & 0.080 & $* *$ & 0.075 & 0.114 & \\
\hline \multicolumn{13}{|l|}{ Marital Status } \\
\hline Married & 0.639 & 0.042 & $* * *$ & 0.726 & 0.048 & $* * *$ & 0.398 & 0.110 & $* * *$ & 0.358 & 0.147 & $* *$ \\
\hline Widowed & 0.173 & 0.066 & $* *$ & 0.157 & 0.079 & $* *$ & 0.044 & 0.167 & & 0.234 & 0.183 & \\
\hline Divorced/Sep & 0.125 & 0.039 & $* * *$ & 0.101 & 0.045 & $* *$ & 0.152 & 0.093 & & 0.294 & 0.147 & $*$ \\
\hline Family size & 0.059 & 0.015 & $* * *$ & 0.051 & 0.018 & $* * *$ & 0.093 & 0.036 & $* *$ & 0.027 & 0.057 & \\
\hline \multicolumn{13}{|l|}{ Region (ref. West) } \\
\hline Northeast & 0.201 & 0.046 & $* * *$ & 0.195 & 0.052 & $* * *$ & 0.231 & 0.132 & $*$ & 0.260 & 0.145 & $*$ \\
\hline Midwest & 0.144 & 0.041 & $* * *$ & 0.119 & 0.047 & $* *$ & 0.127 & 0.112 & & 0.481 & 0.135 & $* * *$ \\
\hline South & 0.197 & 0.038 & $* * *$ & 0.161 & 0.045 & $* * *$ & 0.254 & 0.094 & $* * *$ & 0.278 & 0.110 & $* *$ \\
\hline \multicolumn{13}{|l|}{ Race (ref. White) } \\
\hline Black & -0.058 & 0.045 & & -0.045 & 0.053 & & -0.028 & 0.098 & & -0.248 & 0.324 & \\
\hline Others & 0.030 & 0.070 & & 0.025 & 0.080 & & -0.338 & 0.220 & & 0.200 & 0.192 & \\
\hline \multicolumn{13}{|l|}{ Education (ref. < HS) } \\
\hline High School & 0.134 & 0.062 & $* *$ & 0.172 & 0.068 & $* *$ & 0.045 & 0.205 & & -0.053 & 0.184 & \\
\hline Some College & 0.235 & 0.060 & $* * *$ & 0.267 & 0.066 & $* * *$ & 0.160 & 0.200 & & 0.037 & 0.186 & \\
\hline College & 0.165 & 0.064 & $* *$ & 0.210 & 0.071 & $* * *$ & 0.102 & 0.205 & & -0.100 & 0.185 & \\
\hline Grad/Prof Degree & 0.268 & 0.069 & $* * *$ & 0.300 & 0.081 & $* * *$ & 0.078 & 0.203 & & 0.359 & 0.197 & $*$ \\
\hline Log Income & 0.044 & 0.014 & $* * *$ & 0.036 & 0.017 & $* *$ & 0.024 & 0.044 & & 0.068 & 0.035 & $*$ \\
\hline Homeowner & 0.088 & 0.034 & $* *$ & 0.098 & 0.038 & $* *$ & 0.086 & 0.085 & & 0.030 & 0.125 & \\
\hline \multicolumn{13}{|l|}{ Employment } \\
\hline Govt. Employed & -0.147 & 0.038 & $* * *$ & & & & & & & & & \\
\hline Self Employed & 0.634 & 0.055 & $* * *$ & & & & & & & & & \\
\hline Intercept & 4.366 & 0.151 & $* * *$ & 4.432 & 0.175 & $* * *$ & 5.102 & 0.483 & $* * *$ & 4.824 & 0.397 & $* * *$ \\
\hline Observation & 4296 & & & 3168 & & & 793 & & & 335 & & \\
\hline $\mathrm{R}$ square & 0.1721 & & & 0.153 & & & 0.1036 & & & 0.1683 & & \\
\hline
\end{tabular}

$* * * \mathrm{p}<.01, * * \mathrm{p}<.05, * \mathrm{p}<.10$ 
Table 3. Regression: Insurance Contribution as a percentage of annual expense

\begin{tabular}{|c|c|c|c|}
\hline & Coef. & St. Error & Sig. \\
\hline \multicolumn{4}{|l|}{ Age (ref.: >51) } \\
\hline Age $<33$ & -0.329 & 0.051 & $* * *$ \\
\hline Age 3341 & -0.238 & 0.046 & $* * *$ \\
\hline Age 4251 & -0.170 & 0.045 & $* * *$ \\
\hline Male (ref.: Female) & 0.009 & 0.034 & \\
\hline \multicolumn{4}{|c|}{ Marital Status (ref.: Single) } \\
\hline Married & 0.238 & 0.046 & $* * *$ \\
\hline Widowed & 0.042 & 0.073 & \\
\hline Divorced/Sep & 0.003 & 0.042 & \\
\hline Family size & 0.060 & 0.015 & $* * *$ \\
\hline \multicolumn{4}{|l|}{ Region (ref. West) } \\
\hline Northeast & 0.293 & 0.051 & $* * *$ \\
\hline Midwest & 0.278 & 0.045 & $* * *$ \\
\hline South & 0.333 & 0.042 & $* * *$ \\
\hline \multicolumn{4}{|l|}{ Race (ref.: White) } \\
\hline Black & -0.013 & 0.050 & \\
\hline Others & 0.019 & 0.071 & \\
\hline \multicolumn{4}{|c|}{ Educational (ref. < High School) } \\
\hline High School & 0.023 & 0.067 & \\
\hline Some College & -0.022 & 0.068 & \\
\hline College & -0.269 & 0.066 & $* * *$ \\
\hline Grad/Prof Degree & -0.246 & 0.070 & $* * *$ \\
\hline Log Income & -0.129 & 0.016 & $* * *$ \\
\hline Homeowner & -0.028 & 0.036 & \\
\hline \multicolumn{4}{|c|}{ Employer Type (ref. Private) } \\
\hline Self Employed & 0.335 & 0.060 & $* * *$ \\
\hline Govt. Employed & -0.142 & 0.041 & $* * *$ \\
\hline Intercept & -3.059 & 0.166 & $* * *$ \\
\hline Observation & 4295.000 & & \\
\hline $\mathrm{R}$ square & 0.105 & & \\
\hline
\end{tabular}


Table. 4. Probit: Likelihood of participation in PPO plans

\begin{tabular}{|c|c|c|c|c|}
\hline & Coef. & St. Error & Marg.Effect & Sig. \\
\hline \multicolumn{5}{|l|}{ Age (ref.: >51) } \\
\hline Age $<33$ & 0.145 & 0.089 & 0.052 & \\
\hline Age 3341 & 0.219 & 0.082 & 0.076 & $* * *$ \\
\hline Age 4251 & 0.135 & 0.079 & 0.048 & $*$ \\
\hline Male (ref.: Female) & -0.083 & 0.059 & -0.03 & \\
\hline \multicolumn{5}{|c|}{ Marital Status (ref.: Single) } \\
\hline Married & 0.030 & 0.080 & 0.011 & \\
\hline Widowed & -0.195 & 0.144 & -0.073 & \\
\hline Divorced/Sep & 0.116 & 0.076 & 0.041 & \\
\hline Family size & -0.024 & 0.030 & -0.008 & \\
\hline \multicolumn{5}{|l|}{ Region (ref.: West) } \\
\hline Northeast & -0.759 & 0.089 & -0.292 & $* * *$ \\
\hline Midwest & 0.019 & 0.075 & 0.007 & \\
\hline South & 0.244 & 0.072 & 0.086 & $* * *$ \\
\hline \multicolumn{5}{|l|}{ Race (ref.: White) } \\
\hline Black & -0.113 & 0.095 & -0.042 & \\
\hline Others & 0.097 & 0.139 & 0.099 & \\
\hline \multicolumn{5}{|c|}{ Education (ref.: < High School) } \\
\hline High School & 0.589 & 0.137 & 0.194 & $* * *$ \\
\hline Some College & 0.650 & 0.135 & 0.221 & $* * *$ \\
\hline College & 0.886 & 0.141 & 0.276 & $* * *$ \\
\hline Grad/Prof Degree & 0.820 & 0.149 & 0.246 & $* * *$ \\
\hline Log Income & 0.083 & 0.028 & 0.03 & $* * *$ \\
\hline Homeowner & -0.055 & 0.066 & -0.019 & \\
\hline \multicolumn{5}{|c|}{ Employer Type (ref.: Private) } \\
\hline Self Employed & -0.204 & 0.100 & -0.076 & $* *$ \\
\hline Govt. Employed & -0.189 & 0.070 & -0.071 & $* * *$ \\
\hline Intercept & -1.097 & 0.299 & & $* * *$ \\
\hline Observation & 2545 & & & \\
\hline Pseudo R square & 0.1079 & & & \\
\hline
\end{tabular}

$* * * \mathrm{p}<.01, * * \mathrm{p}<.05, * \mathrm{p}<.10$ 